\title{
Case Report (Acute Iron Toxicity)
}

\section{Mohamed Enara* \\ Clinical Toxicology, Poison Control Center Cairo University, Egypt}

*Corresponding author: Mohamed Enara, MD Clinical Toxicology, Poison Control Center Cairo

University, Cairo, Egypt, Email: moennara@gmail.com

\section{Case Report}

Volume 5 Issue 2

Received Date: May 08, 2020

Published Date: June 16, 2020

DOI: $10.23880 /$ act- 16000185

\section{Abstract}

Acute poisoning is a critical situation that needs rapid history taking, investigations and quick intervention at the Poison Control ER. Best treatment protocols should be started as soon as a diagnosis is made, but general ABC techniques should not wait for such a diagnosis. I am presenting two cases of acute poisoning attended the Poison Control Center. The case history and signs and symptoms are described. Maneuvers for acute intervention and investigations done. Outcome and recommendations for each case is documented.

Keywords: Acute Iron Toxicity; TCA Overdose

\section{Case 1}

A 3 years old boy presented to the toxicology center of Cairo University, Egypt complaining of lethargy and bloody vomitus of acute onset. He was found under the bed of the parents, lethargic and pale. The history from his parents revealed that he vomited twice at home just before admission, with blood in the vomitus too. Questioning his parents, there was no history of previous allergic manifestations, and he was not under any medications. The mother had a baby age 3 weeks on presentation. O/E: vitals; pulse 136 , BP $75 / 50$, respiratory rate 32 , and temp was 37.3. Chest was clear to auscultation with equal sounds bilaterally. Neck was supple with excessive use of accessory respiratory muscles, with no lymphadenopathy. Abdomen examination showed diffuse tenderness with increased bowel sounds and no organomegaly. Rectal examination showed maroon bloody stools. Nailbeds were pale, hands and feet were cold and clammy. Neurological examination showed $1+$ reflexes, slow response to questions. Pupils were $3 \mathrm{~mm}$ symmetrically reactive. ECG was done which revealed sinus tachycardia. Gastric lavage was performed to the child. Investigations gave the initial following results: $\mathrm{Hb} 13.4 \mathrm{~g} /$ dl; WBC $16,700 / \mathrm{mm}^{3}$; platelets $195,000 / \mathrm{mm}^{3}$; glucose was $194 \mathrm{mg} / \mathrm{dl}$ on random check; Na 141; K 4.2; Cl 106; PT 15.9 sec; $\mathrm{pH}$ 7.23; $\mathrm{HCO}_{3}$ 15; BUN 20; Creatinine 0.7. Results are suggestive of metabolic acidosis with high anion gap of 20. Glucose was high with WBC above normal range too. These findings together with the clinical picture of bloody vomitus, led to a differential diagnosis of the following; Iron ingestion; isopropyl alcohol present in perfumes (excluded by odor); aspirin ingestion(excluded initially by absence of any aspirin tablet remains) and hydrogen fluoride present in spot cleaners and removers (initially excluded due to absence of convulsions). Our main stress was on iron toxicity and salicylate overdose. The child was given a crystalloid solution for his state of hypotension and shock. Salicylate level was routinely done and was negative. Serum iron level was $260 \mathrm{ug} / \mathrm{dl}$ after 4 hours of ingestion [1]. Gastric lavage was done again and an abdominal X-ray was requested, which showed pill fragments and concretions in the stomach. After another gastric lavage session, another X-ray picture showed pill fragments were still in the stomach. At this point a decision was made to do whole bowl irrigation to the case. This was done using a polyethylene glycol solution in a dose of $500 \mathrm{ml} / \mathrm{h}$. The child passed clear stools after about 5 hours, with normal abdominal X-ray and iron serum level of 110ug/ $\mathrm{dl}$ at this point. Follow up of the child before discharge was done through serial liver function tests and PT which came within normal range. The child was discharged on the next day, and came back for barium meal after 5 weeks to rule out scarring of the GIT [2]. 


\section{Recommendations and Conclusions}

Whole bowl irrigation is a very useful method of decontamination in this case because of presence of concretions, and failure of repeated gastric lavage to remove the pills. Repeated abdominal X-ray is indicated to follow the process of decontamination.

\section{Case 2}

A 30 years old female was found by her friend at home at 1 a.m. obtunded and unresponsive on the floor. She was taken to emergency department immediately. On initial evaluation the patient was still unresponsive, vitals were; BP 80/50; pulse 120; regular; temperature 37.4. Pupils were fixed at about $4 \mathrm{~mm}$, unresponsive to light with $2+$ tendon reflexes. Chest was clear; abdomen was soft with hypoactive bowl sounds and no organomegaly [3]. Her friend gave a history that the patient was asthmatic and under an inhaler treatment. No history of abuse, but she was also taking medications for anxiety disorders. No other medications were known to the friend. Lab. results were taken and the initial results were: ECG showed prolonged QRS of $110 \mathrm{msec}$, long QT interval with 120 beat/minute. WBC 9.6; Hb 14.9; platelets 420,000; $\mathrm{Na} 140 ; \mathrm{K} \mathrm{3.5;} \mathrm{Cl} 101 ; \mathrm{HCO}_{3} 25$; BUN 18; Creatinine 1.3 and random glucose was $125 . \mathrm{pH}$ was 7.27; $\mathrm{PCO}_{2} 52 \mathrm{mmHg} ; \mathrm{PO}_{2}$ 89. Initial management was quickly done as follows: Airway control was done and intubation was performed to the patient. Respiratory acidosis and low PO2 were present and so she needed assistance in protecting the airways. A neuromuscular blocker was used to avoid vagal effects instead of succinyl choline. The patient received a crystalloid solution for her hypotension, and the treatment was then shifted to removal of the toxic substance. The friend brought an empty bottle of a tricyclic antidepressant drug (tryptizol). This was coinciding with the physical findings of the patient of a wide QRS interval and the anticholinergic symptoms and unresponsiveness of the patient. Activated charcoal was given after a protected lavage session was done through the orogastric tube. Sodium bicarbonate in a dose of $50 \mathrm{mEq}$ was initiated [4]. The next ECG of the patient after about 3 hours from bicarbonate treatment showed normal QRS interval, and the $\mathrm{pH}$ raised to be 7.48. The patient was under medical supervision on the monitor, and no use of diazepam was made owing to the absence of seizures, which could complicate a case of tricyclic antidepressant overdose. The patient was discharged after 2 days with complete conscious level and normal laboratory findings made the day before.

\section{Recommendations and Conclusions}

It is advised to use sodium bicarbonate quickly to correct the acidosis and wide QRS changes of the tricyclic antidepressants acute toxicity, in addition to other routine maneuvers.

\section{References}

1. Gumber MR, Kute VB, Shah PR, Vanikar AV, Patel HV, et al. (2013) Successful treatment of severe iron intoxication with gastrointestinal decontamination, deferoxamine, and hemodialysis. Ren Fail 35(5): 729-731.

2. Chang TP, Rangan C (2011) Iron poisoning: a literaturebased review of epidemiology, diagnosis, and management. Pediatr Emerg Care 27(10): 978-985.

3. Levitt MA, Sullivan JB, Owens SM, Burnham L, Finley PR (1986) Amitriptyline plasma protein binding: effect of plasma $\mathrm{pH}$ and relevance to clinical overdose. Am J Emerg Med 4(2): 121-125.

4. Weinbroum A, Heifetz M, Bursztein S (1985) [Poisoning by tricyclic antidepressants and antidotes]. Harefuah 109(5-6): 132-134.

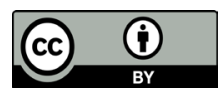

